ISSN: 1410-8917

Jurnal Kimia

-Sains \&

Aplikasi

e-ISSN: 2597-9914
Jurnal Kimia Sains dan Aplikasi Journal of Scientific and Applied Chemistry

Journal homepage: http://ejournal.undip.ac.id/index.php/ksa

\title{
Antioxidant and Antimicrobial Screening of Endophytic Fungi Culture Filtrate from Purwoceng (Pimpinella Alpina Molk) Leaf
}

\author{
Agustina L. N. Aminin ${ }^{\mathrm{a},{ }^{*}}$, Nur Cahyanti ${ }^{\mathrm{a}}$, Alfina Sari ${ }^{\mathrm{a}}$, Nies Suci Mulyani ${ }^{\mathrm{a}}$, \\ Bambang Cahyono ${ }^{\mathrm{a}}$ \\ ${ }^{\text {a }}$ Chemistry Department, Faculty of Sciences and Mathematics, Diponegoro University, Tembalang, Semarang, Indonesia \\ * Corresponding author: agustina.aminin@live.undip.ac.id \\ https://doi.org/10.14710/jksa.23.9.319-324
}

\section{Article Info}

Article history:

Received: $21^{\text {st }}$ April 2020 Revised: $13^{\text {th }}$ August 2020

Accepted: $7^{\text {th }}$ September 2020

Online: $30^{\text {th }}$ September 2020

Keywords:

purwoceng; endophyte;

fungi; antioxidant;

antimicrobial

\begin{abstract}
This is a preliminary study to determine the bioactivity potential of purwoceng leaf endophytic fungal metabolites. Endophytic fungi were isolated from purwoceng leaf and their secondary metabolite from culture filtrate were subjected to identify the antimicrobial, antioxidant, and phytochemical screening. The antioxidant activity was screened by scavenging 2,2-diphenyl-1-picrylhydrazyl (DPPH). The antimicrobial activity was screened using a good agar method toward Salmonella typhi, Escherichia coli, Bacillus subtilis, Staphylococcus aureus, dan Candida albicans. This study obtained five distinctive endophytic fungi isolates named A, B, C, D, and $\mathrm{E}$. The endophytic fungal culture filtrate of $\mathrm{C}$ has the most extensive antimicrobial activity with phytochemical screening showing alkaloids, saponins, and terpenoids. The antioxidant potential of all culture filtrates seemed low because the DPPH amount was interfered with by pigment compounds. Culture filtrate of fungi A showed the highest antioxidant activity and contained phenolic and alkaloid compounds.
\end{abstract}

\section{Introduction}

Purwoceng (Pimpinella Alpina Molk) is a native Indonesian medicinal plant that lives endemically in the highlands such as the Dieng Plateau and Mount Lawu in Central Java, Pangrango Mountain and Galunggung Mountain in West Java, and in the Tengger and Iyang Mountains in East Java [1]. There are quite a lot of studies on the phytochemical of Pimpinella Alpina Molk. Purwoceng contains bergapten, isobergapten, and saponin, all included in the furanocoumarin group used in the modern medicine industry as analgesic antipyretic, sedative, worming, antifungal, antibacterial, and anticancer drugs [2]. Nurcahyanti et al. [3] has researched the antimicrobial activity of Purwoceng root oil extract on three Candida species as well as several gram-positive and gram-negative bacteria that are pathogenic compared to conventional antibiotics (Vancomycin and Streptomycin). The results show that Purwoceng root oil extracts have moderate antimicrobial activity when compared to conventional antibiotics.
Its endemic nature makes purwoceng very difficult to grow outside of its habitat. Therefore, exploring its potential in specific fields requires more straightforward techniques to easily extract its bioactive compounds without requiring an abundant amount of plants, so it does not endanger purwoceng sustainability. The technique is the isolation of endophytic fungi. Endophytes are microorganisms that grow in host plant tissues and produce bioactive compounds similar to their hosts without causing specific disease symptoms [4]. Endophytes are very easy to grow in large amounts and swiftly without the need for abundant plants. This causes endophytic isolation techniques to be an effective alternative to producing bioactive compounds from plants without endangering their habitat.

Research by Wilson et al. [5] shows that purwoceng endophytic bacteria have potential as antimicrobial agents by inhibiting Staphylococcus aureus with a diameter of inhibition $1.72 \mathrm{~cm}$. Purwestri et al. [6] has also conducted endophytic microbial exploration of Purwoceng endophytic bacteria. Endophytic fungi isolated from flowers, fruits, leaves, and twigs of the 
cinnamon plant from Bogor, West Java, Indonesia, reported their potential antioxidant and anti-diabetic properties [7]. Efforts to isolate endophytic bacteria from Purwoceng have been through reasonably a lot. However, so far, there have not been any studies that have focused on the isolation and testing of antimicrobial and antioxidant activity of endophytic fungi from the Purwoceng plant.

\section{Methodology}

This research was conducted at the Biochemistry Laboratory, Faculty of Science and Mathematics, Diponegoro University.

\subsection{Materials and Equipment}

Purwoceng leaves were obtained from a farmer at Dieng plateau, Central Java. The pathogenic microbes used are Escherichia coli, Salmonella typhi, Bacillus subtilis, Staphylococcus aureus, Candida albicans InaCC Y157 from the Indonesian Institute of Sciences. All of the materials are purchased from Merck: Potato Dextrose Broth, bacto agar, peptone, yeast extract, ethanol, amyl alcohol, chloramphenicol, ketoconazole, Lactophenol Cotton Blue, $\mathrm{HCl}$ p.a, $\mathrm{H}_{2} \mathrm{SO}_{4}, \mathrm{NaOH}, \mathrm{FeCl}_{3} .6 \mathrm{H}_{2} \mathrm{O}, \mathrm{BaCl}_{2}$, chloroform, anhydrous acetic acid, Mayer's reagent, and Dragendorf's reagent

\subsection{Isolation and purification of endophytic fungi}

The isolation and purification of endophytic fungi in this study followed Tolulope et al. [8]. All work in this step is carried out aseptically in Laminar Air Flow. The isolation of endophyte begins with the preparation of samples through washing purwoceng leaves using flowing distilled water. Then leaf samples are cut about $1 \times 1 \mathrm{~cm}$. The leaf pieces were then immersed in $70 \%$ ethanol for 5 minutes, $\mathrm{NaClO} 5 \%$ for 3 minutes, and sterile distilled water for 5 minutes with three repetitions, then drying. Sterile leaf pieces are placed on the Potato Dextrose Agar (PDA) medium, which has been given $150 \mathrm{mg} / \mathrm{L}$ chloramphenicol and incubated at $37^{\circ} \mathrm{C}$ until the fungal growth is visible. Afterward, to make a single endophytic fungus, each visible colony was cultured on a new PDA medium and incubated until growth. The following growth profile was performed by observing the morphology and color of hyphae every 8 hours.

\subsection{Production of secondary metabolites in a liquid medium}

The secondary metabolites of endophytic fungi were produced by cultivating the fungi in potato dextrose broth at $37^{\circ} \mathrm{C}$ with a shaker at $125 \mathrm{rpm}$. The metabolites were harvested when the fungal growth was estimated at the end of the stationary or early death phases. Based on previous observation, each fungus' expected early death phase showed by the changing color of hyphae and spores that become darker (brown or black). The cultivation was stopped at this stage, then culture separated from their mycelia by filtration afterward was centrifuged at $6000 \mathrm{rpm}$ for 20 minutes. The fungal culture filtrate was collected and keep in the freezer for the next work.

\subsection{Phytochemical screening of endophytic fungal culture filtrate}

Alkaloid and saponin tests were carried out following the Harborne [9] method, while flavonoid, phenolic, terpenoid, steroid, and tannin tests follow the method of Bhardwaj et al. [10]. The alkaloid test is carried out through $3 \mathrm{~mL}$ of endophytic culture filtrate added with a few drops of HCN $2 \mathrm{~N}$. The solution is divided into three equal parts. Each section was tested with a few drops of Mayers reagent, Dragondroffs reagent, and Wagner's reagent. Positive characteristics that contain alkaloids are the formation of a white layer in Mayers reagents and red brick deposits in Dragendroffs reagents.

The froth test tests - the presence of saponins. One $\mathrm{mL}$ of filtrate was dissolved with distilled water, shaken vigorously, and allowed to stand for 10 minutes. The presence of saponins is indicated by stable froth after $\mathrm{HCl} 2 \mathrm{~N}$ drops.

Flavonoid Test. A total of $1 \mathrm{~mL}$ filtrate plus 5-10 drops of $\mathrm{HCl} 2 \mathrm{~N}$ and magnesium powder were heated for 2 minutes. Then the addition of $2 \mathrm{~mL}$ of amyl alcohol. If it positively contains flavonoids will form pink, yellow, or orange.

Phenolic. One $\mathrm{mL}$ of filtrate was added with a few drops of $5 \%$ iron chloride solution. The dark green color indicates the presence of phenolic compounds.

Terpenoids. One $\mathrm{mL}$ of filtrate was added $2 \mathrm{~mL}$ chloroform and two drops of acetic anhydride-the addition of 3 drops of concentrated $\mathrm{H}_{2} \mathrm{SO}_{4}$ to form a layer. If positive contains terpenoids, reddish-brown sediments will form at the interface layer.

Steroids. Libermann-Burchard reaction was carried out to test the presence of steroids. One $\mathrm{mL}$ of filtrate was added $1 \mathrm{~mL}$ of chloroform solution and two drops of acetic anhydride and two drops of concentrated $\mathrm{H}_{2} \mathrm{SO}_{4}$. If it is positive to contain steroids, a red upper and yellow lower layer with green fluorescence forms.

Tannin. One $\mathrm{mL}$ of filtrate was added 5-10 drops of $1 \% \mathrm{FeCl}_{3}$. A positive test if blackish-blue is formed, which disappears when adding a small number of watery $\mathrm{H}_{2} \mathrm{SO}_{4}$ and is followed by the formation of a yellowishbrown precipitate.

\subsection{Screening antioxidant activity of endophytic fungal culture filtrate}

The endophytic fungal culture filtrate was tested for its DPPH scavenging capacity. The stock solution for radical was prepared by dissolving $1.9 \mathrm{mg} \mathrm{DPPH}$ in 50 $\mathrm{mL}$ methanol and homogenized. DPPH solution is used as a reagent for screening antioxidant activity. One $\mathrm{mL}$ of each filtrate was put into a vial bottle, and $3 \mathrm{~mL}$ of DPPH solution was added. The solution was incubated at room temperature for 30 minutes in a dark place, and color changes were observed. The color will change from purple to yellow if the sample has antioxidants. The highest antioxidant activity was measured by decreasing the absorbance of DPPH and the percent inhibition of the sample against DPPH. DPPH absorbance was measured 
at a wavelength of $517 \mathrm{~nm}$. Ascorbic acid $(15 \mu \mathrm{g} / \mathrm{mL})$ was used as positive control and sterile PDB as a negative control.

\subsection{Screening of endophytic fungi antimicrobial activity}

The endophytic fungal culture filtrate was tested for antimicrobial activity by the well plate method [11]. First, each test microbe was inoculated in a liquid medium (Zobell for bacteria and PDB for Candida) then measured the OD (Optical Density) every two hours with a spectrophotometer at a wavelength of $600 \mathrm{~nm}$. Measurements were made until the microbial suspension was equal to the standard of $0.5 \mathrm{McF}$ arland (the mixture of $0.05 \mathrm{~mL}$ of $1.175 \%$ barium chloride dihydrate with $9.95 \mathrm{~mL}$ of $1 \%$ sulfuric acid), which are $10^{8}$ cells $/ \mathrm{mL}$ for bacteria and $1.5 \times 10^{6}$ cells $/ \mathrm{mL}$ for Candida. Pathogen microbes $(100 \mu \mathrm{L})$ equivalent to 0.5 McFarland standard were inoculated on Zobell agar for Escherichia coli, Salmonella typhi, and Bacillus subtilis, Staphylococcus aureus, and PDA medium for Candida albicans InaCC Y1571, then spread with spreaders. Additionally, wells were made in each quadrant using a cork borer with a diameter of $5 \mathrm{~mm}$. To this is added 100 $\mu \mathrm{L}$ of endophytic fungal filtrate into the well. As a positive control, $50 \mu \mathrm{g} / \mathrm{mL}$ chloramphenicol is used, and for negative control is used sterile distilled water. Incubation was carried out for 24 hours at $37^{\circ} \mathrm{C}$, and the diameter of the inhibition zone was measured with a ruler in millimeter.

\section{Results and Discussion}

The bioactive potential of endophytic fungal metabolites from the purwoceng plant was carried out through isolating the endophytic fungi from purwoceng leaves. The secondary metabolites of endophytic fungi
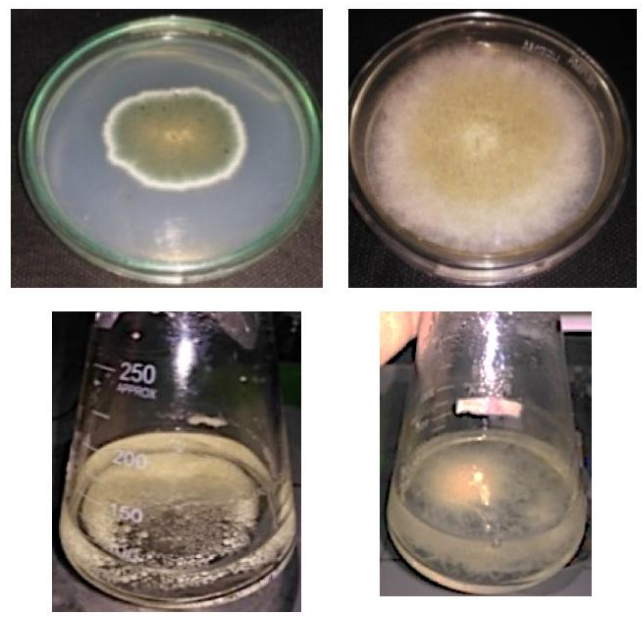

A

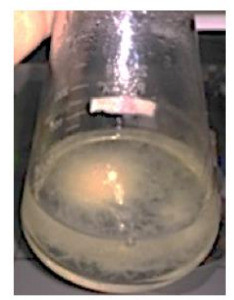

B
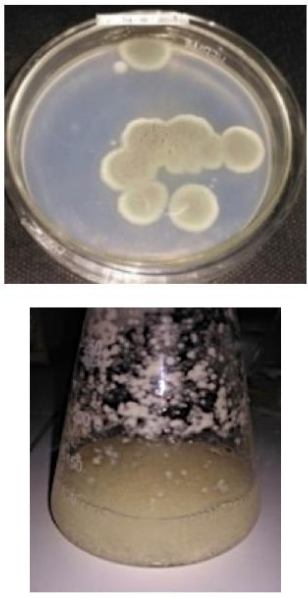

C culture filtrate are the target of this study. The bioactive screening was performed for their antimicrobial and antioxidant activity. Qualitative phytochemical screening is also executed to check the chemical type compound.

\subsection{Isolation and Purification Endophytic Fungi from Purwoceng Leaf}

Endophytic fungi isolation from purwoceng leaf carried out using the PDA medium with the addition of chloramphenicol to prevent the growth of bacteria. Several fungi colonies that emerge around leaf cut then separate to get single fungi. Five single fungi have been successfully isolated, which show different morphological characteristics both on solid and liquid medium. Endophytic fungi in liquid medium were incubated using a rotary shaker to regulate oxygen supply by aeration. Oxygen circulation in the medium is always renewed and affects the growth of microorganism cells [12]; this condition may contribute to the different fungal morphologies in both mediums.

This study's observation of fungal growth profiles was carried out based on the hyphae appearance and spore colors to estimate the growth phase and secondary metabolites' production. In general, the fungal growth profile in the logarithmic phase is characterized by white hyphae growth. It is known that secondary metabolites are produced at the beginning of the stationary phase. To ensure that sufficient secondary metabolites are produced for screening, the culture filtrate is harvested in the phase of death. The change in the color of the hyphae, which gets darker and black spores to begin to appear, is used as a harvest period, assumed to be the phase leading to death.

Figure 1. Five isolates of endophytic fungi of Purwoceng leaf have been isolated and named A, B, C, D, and E. In this figure, each isolate is estimated at the logarithmic phase, which is occupied by white hyphae. 
Table 1. The estimation growth profile of endophytic fungi in PDB

\begin{tabular}{|c|c|c|c|}
\hline Endophyte & Logarithmic & Stationer & Death phase \\
\hline A & $\begin{array}{l}1-10 \text { days } \\
\text { small white spherical } \\
\text { mycelium }\end{array}$ & $\begin{array}{l}10-15 \\
\text { days } \\
\text { Yellowish } \\
\text { mycelium } \\
\text { ball }\end{array}$ & $\begin{array}{l}15-20 \text { days } \\
\text { Mycelium turn } \\
\text { black }\end{array}$ \\
\hline B & $\begin{array}{l}1-3 \text { days } \\
\text { small, spherical white } \\
\text { mycelium surrounded } \\
\text { by fibrous mycelium }\end{array}$ & $\begin{array}{l}3 \text { - } 5 \text { days } \\
\text { brownish- } \\
\text { white } \\
\text { mycelium }\end{array}$ & $\begin{array}{c}5-7 \text { days } \\
\text { blackish brown } \\
\text { mycelium }\end{array}$ \\
\hline $\mathrm{C}$ & $\begin{array}{l}1 \text { - } 10 \text { days } \\
\text { white mycelium with a } \\
\text { small and irregular } \\
\text { round shape }\end{array}$ & $\begin{array}{c}10-15 \\
\text { days } \\
\text { mycelium } \\
\text { turns } \\
\text { yellow- } \\
\text { brown }\end{array}$ & $\begin{array}{l}15 \text { - } 20 \text { days } \\
\text { Brown } \\
\text { mycelium }\end{array}$ \\
\hline D & $\begin{array}{l}\text { 1 - } 16 \text { days } \\
\text { white hyphae in the } \\
\text { form of small balls } \\
\text { surrounded by } \\
\text { perpendicular hairs }\end{array}$ & $\begin{array}{l}16-38 \\
\text { days } \\
\text { Slightly } \\
\text { yellow } \\
\text { mycelium }\end{array}$ & $\begin{array}{c}38 \text { - } 47 \text { days } \\
\text { mycelium hairs } \\
\text { wither, and the } \\
\text { hyphae turn } \\
\text { brown }\end{array}$ \\
\hline $\mathrm{E}$ & $\begin{array}{l}1-9 \text { days } \\
\text { Small ball white } \\
\text { mycelium }\end{array}$ & $\begin{array}{l}9-15 \text { days } \\
\text { Brownies } \\
\text { white } \\
\text { mycelium }\end{array}$ & $\begin{array}{l}15 \text { - } 19 \text { days } \\
\text { Brown } \\
\text { mycelium }\end{array}$ \\
\hline
\end{tabular}

\subsection{Phytochemical screening}

The qualitative analysis of culture filtrate of fungal metabolites showed alkaloids, phenolics, saponins, and terpenoids. However, the flavonoids, steroids, and tannins are not found in culture filtrate.

Table 2. The phytochemical screening of endophytic fungi culture filtrate.

\begin{tabular}{ccccccc}
\hline \multirow{2}{*}{ Metabolites } & \multicolumn{5}{c}{ Endophyte } \\
\cline { 2 - 6 } & A & B & C & D & E \\
\hline flavonoid & - & - & - & - & - \\
alkaloid & + & - & + & - & - \\
saponin & - & + & + & + & - \\
terpenoid & - & - & + & - & - \\
phenolic & + & + & - & + & + \\
steroid & - & - & - & - & - \\
tannin & - & - & - & - & - \\
\hline
\end{tabular}

The initial screening of fungal metabolite compounds in culture filtrates of endophytic fungi from Purwoceng leaves showed various fungal metabolites such as alkaloids, phenolic, saponins, and terpenoids (Table 2). Terpenoids are only present in the endophytic $\mathrm{C}$ filtrate culture, whereas phenolics are found in most endophytes culture filtrate, contributing to the antioxidant activity. While saponin in culture B, C, and D could sign the high activity of antimicrobial.

\subsection{Screening antioxidant activity}

Screening is carried out to select fungal isolates that produce metabolites with the highest antioxidant activity. The antioxidant assay was performed using a scavenging DPPH radical method. Screening antioxidant activity of endophytic fungi A, B, C, D, and D is carried out in two growth phases: logarithmic and stationary.
Many primary metabolite compounds are produced at the logarithmic phase, such as carbohydrates, proteins, fats, and nucleic acids. In the stationary phase, secondary metabolites are produced, which usually act as active compounds with pharmacologically essential roles [13]. The results of antioxidant screening can be seen in table 3 and table 4 .

Table 3. Antioxidant screening of endophytic fungal culture filtrate in the logarithmic phase

\begin{tabular}{cccc}
\hline Isolate & $\begin{array}{c}\text { DPPH } \\
\text { absorbance }\end{array}$ & $\begin{array}{c}\text { Sample } \\
\text { absorbance }\end{array}$ & $\begin{array}{c}\text { Percent } \\
\text { inhibition }\end{array}$ \\
\hline A & 0.465 & 0.234 & 0.005 \\
B & 0.465 & 0.736 & -0.006 \\
C & 0.465 & 1.600 & -0.024 \\
D & 0.465 & 0.433 & 0.0007 \\
E & 0.465 & 1.300 & -0.0179 \\
\hline
\end{tabular}

Table 4. Antioxidant screening of endophytic fungal culture filtrate in the stationary phase

\begin{tabular}{cccc}
\hline Isolate & $\begin{array}{c}\text { DPPH } \\
\text { absorbance }\end{array}$ & $\begin{array}{c}\text { Sample } \\
\text { absorbance }\end{array}$ & $\begin{array}{c}\text { Percent } \\
\text { inhibition }\end{array}$ \\
\hline A & 0.465 & 0.207 & 0.006 \\
B & 0.465 & 0.603 & -0. \\
C & 0.465 & 1.484 & -1.019 \\
D & 0.465 & 0.498 & -0.033 \\
E & 0.465 & 1.518 & -1.053 \\
\hline
\end{tabular}

The 2,2-diphenyl-1-picrylhydrazyl (DPPH) compound is a stable radical compound with unpaired valence electrons on the nitrogen atom bridge [14]. The DPPH radical compound is purple and has a strong absorbance at a wavelength of $517 \mathrm{~nm}$. The principle of the DPPH test method is the hydrogen donor reaction from antioxidant compounds to free radical compounds. The parameter used to show screening for antioxidant activity is a decrease in DPPH radical absorbance. The absorbance value indicates the amount of DPPH contained in the test solution. The DPPH radical compound will be reduced after reacting with antioxidant compounds and produce a more stable diphenyl picrylhydrazine compound [15]. DPPH compounds in the test solution will be reduced so that the absorbance decreases. This can be used to a parameter that the sample with the highest absorbance difference with radical DPPH control will have the highest antioxidant activity.

Based on observations in Tables 3 and 4, it is shown that the antioxidant potential of all culture filtrates seemed low. The highest difference in absorbance was shown by endophytic fungi A culture of stationary phase. The difference in absorbance given by endophytic fungi A in the stationary phase is more significant than logarithmic. It is suspected that compounds that act as antioxidants, such as phenolic groups in A culture filtrate (table 2) that give the highest contribution to this activity.

Endophytic D culture filtrate also showed DPPH radical reduction activity but with less activity in the logarithmic phase, but it had an absorbance difference 
with a minus digit. Similar data were also shown by endophytic fungi $\mathrm{B}, \mathrm{C}$, and $\mathrm{E}$, in the logarithmic and stationary phases. These three endophytic fungi showed higher absorbance values compared to the DPPH radical control. This indicates that other compounds besides DPPH are detected at a wavelength of $517 \mathrm{~nm}$ or correspondingly called interference compounds enclosed in the filtrate. A similar minus value of the spectrophotometric absorbance also showed at the determination of DPPH scavenging that was reported by Kumara et al. [16] due to the interference of pigment in freeze-dried berry extract. This phenomenon is consistent with Müller et al. [17], which shows that a brown solution is produced after mixing DPPH with the sample. Liu et al. [18] also mentioned that there was interference between carotenoid compounds and DPPH radicals when measuring at a wavelength of $515 \mathrm{~nm}$, which was marked by the formation of a brown color after the addition of DPPH. Interference can be reduced by changing the wavelength to $540 \mathrm{~nm}$. At that wavelength, DPPH still has a significant absorption so that the brown color does not dominate [18], but some carotenoids (lycopene and astaxanthin) still absorb at a wavelength of $540 \mathrm{~nm}$ [17]. Based on these data, it can be suspected that all endophytic fungi might contain pigment compounds that interference with DPPH at the same wavelength. The darker mycelium color at the stationary phase (table 1) made the culture filtrate darker with the orange color. This study shows that the antioxidant compound in fungi A relatively high can suppress pigment color interference and produce a positive difference in the DPPH value. It can be concluded that the endophytic fungi from this study can be a pigment producer.

\subsection{Screening Antimicrobial Activity}

Screening of antimicrobial activity aims to determine the endophytic fungal filtrate, which has the highest antimicrobial activity. The method used is a suitable diffusion method based on the measurement of the diameter of the clear zone around the well that shows the filtrate's ability to inhibit test microbes' growth. The pathogen microbes used were Escherichia coli, Salmonella typhi, Bacillus subtilis, Staphylococcus aureus, and Candida albicans InaCC Y1571. The number of microbial cells used has been adjusted to the $0.5 \mathrm{McF}$ arland standard. The results of screening for antimicrobial activity are shown in Table 5.

Table 5. Screening of purwoceng endophytic fungal antimicrobial activity

\begin{tabular}{|c|c|c|c|c|c|c|c|}
\hline \multirow[b]{2}{*}{ Pathogen } & \multicolumn{7}{|c|}{ Inhibitory Zone Diameter (mm) } \\
\hline & A & B & $\mathrm{C}$ & $\mathrm{D}$ & $\mathrm{E}$ & 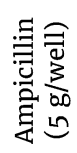 & \begin{tabular}{l} 
I \\
0 \\
0 \\
\multirow{3}{0}{} \\
0 \\
0
\end{tabular} \\
\hline E. coli & 0.0 & 11.0 & 9.0 & 0.0 & 0.0 & 12.0 & 0.0 \\
\hline S. typhi & 0.0 & 0.0 & 10.0 & 0.0 & 0.0 & 14.0 & 0.0 \\
\hline B. subtilis & 0.0 & 0.0 & 11.0 & 0.0 & 0.0 & 10.0 & 0.0 \\
\hline S. aureus & 0.0 & 0.0 & 10.0 & 0.0 & 0.0 & 13.0 & 0.0 \\
\hline C. albicans & 0.0 & 0.0 & 5.5 & 0.0 & 0.0 & ND & 0.0 \\
\hline
\end{tabular}

Table 5 shows that endophytic B filtrate has the potential to be a specific antibiotic for Escherichia coli. The filtrate from endophytic fungi $\mathrm{C}$ has a broad antimicrobial prospect because it can inhibit all test microbes. The filtrate from endophytic fungi A, D, and E did not inhibit the five test microbes, but it does not mean that the endophytic fungi A, D, and $\mathrm{E}$ do not produce antimicrobial compounds. Each microbe will produce antimicrobial compounds, both to kill other microbes and kill similar microbes to survive. Microbes will produce antimicrobial compounds if there are signals from the environment, such as nutrient limitations and signals from harmful neighboring microorganisms [19]. Endophytic fungi filtrate A, D, and $E$ are suspected of containing compounds that inhibit or kill other pathogens besides the five test bacteria in this study.

The screening results for antimicrobial activity showed that the endophytic $\mathrm{C}$ culture filtrate has the most extensive antimicrobial activity. This study's results form the basis for further studies related to an antimicrobial activity with a broad spectrum because this type of antimicrobials is needed to treat infectious cases whose causes are not yet understood.

\section{Conclusion}

Isolation and purification of endophytic fungi from purwoceng leaves obtained five endophytic fungi isolates, viz. A, B, C, D, and E. The morphology of each mushroom is unique, indicating the potential diversity of secondary metabolites. The qualitative analysis of fungal culture filtrate showed the presence of alkaloids, phenolics, saponins, and terpenoids, but flavonoids, steroids, and tannins were not found. All culture filtrates seemed low of antioxidant compounds, with endophytic fungi A show the highest antioxidant activity. The culture filtrate of endophytic A contains alkaloids and phenolic compounds. Screening of antimicrobial activity shows that the filtrate of endophytic $\mathrm{C}$ culture has the most extensive antimicrobial activity. Endophytic C fungi culture filtrate contains alkaloids, saponins, and terpenoids.

\section{Acknowledgment}

This work was made possible and was supported by a grant from DIPA-FSM Diponegoro University No. 4841/UN7.5.8/PM/2019

\section{References}

[1] K. Heyne, Tumbuhan berguna Indonesia, Yayasan Sarana Wana Jaya, Departemen Kehutanan, Jakarta, 1988

[2] Ireng Darwati, Ika Roostika, Status penelitian purwoceng (Pimpinella alpina Molk.) di Indonesia, Buletin Plasma Nutfah, 12, 1, (2016), 9-15 http://dx.doi.org/10.21082/blpn.v12n1.2006.p9-15

[3] Agustina D. R. Nurcahyanti, Issam J. Nasser, Frank Sporer, Bernhard Wetterauer, Ireng D. Kadarso, Jurgen Reichling, Michael Wink, Essential oil composition, in vivo antioxidant, and antimicrobial activities of Pimpinella pruatjan from West Java, Indonesia, The Natural Products Journal, 8, 1, 
(2018), 61-69

https://doi.org/10.2174/2210315507666170620093210

[4] Gary Strobel, Bryn Daisy, Bioprospecting for Microbial Endophytes and Their Natural Products, Microbiology and Molecular Biology Reviews, 67, 4, (2003), 491 https://doi.org/10.1128/MMBR.67.4.491502.2003

[5] Wildiani Wilson, Yekti Asih Pawestri, Langkah Sembiring, Isolasi, karakterisasi dan skrining antimikroba bakteri endofit tanaman Purwoceng (Pimpinella pruatjan Molk), Jurnal Labora Medika, 1, 1, (2017), 1-6

[6] Yekti Asih Purwestri, Nur'aini Kartikasari, Sartika Gunawan Putri, Wildiani Wilson, Langkah Sembiring, Metabolic profiling of endophytic bacteria from Purwoceng (Pimpinella pruatjan Molkend) root and antibacterial activity against Staphylococcus aureus and Pseudomonas aeruginosa, AIP Conference Proceedings, 2016 https://doi.org/10.1063/1.4953537

[7] Eris Septiana, Fauzy Rachman, Yatri Hapsari, Yadi Yadi, Bustanussalam Bustanussalam, Siti Irma Rahmawati, Partomuan Simanjuntak, The potential of Endophytic Fungal Extract Isolated from Cinnamon (Cinnamomum burmannii) as Antidiabetic and Antioxidant, Jurnal Kimia Sains dan Aplikasi, 22, 6, (2019), 275-282 https://doi.org/10.14710/jksa.22.6.275-282

[8] R. Abass Tolulope, Adeleye Isaac Adeyemi, M. Adongbede Erute, T. Seriki Abiodun, Isolation and screening of endophytic fungi from three plants used in traditional medicine in Nigeria for antimicrobial activity, International Journal of Green Pharmacy (IJGP), 9, 1, (2015), 58-62 https://doi.org/10.4103/0973-8258.150929

[9] Jeffrey B. Harborne, Phytochemical Methods, 3Island Press, 1980

[10] Akanksha Bhardwaj, Deeksha Sharma, Nitesh Jadon, Pavan Kumar Agrawal, Antimicrobial and phytochemical screening of endophytic fungi isolated from spikes of Pinus roxburghii, Archives of Clinical Microbiology, 6, 3, (2015), 1-9

[11] Sudipta Roy, Debdulal Banerjee, Isolation of antimicrobial compound by endophytic bacteria from Vinca rosea, International Journal of Current Research, 5, (2010), 47-51

[12] Joanne M. Willey, Linda Sherwood, Christopher J. Woolverton, Prescott, Harley, and Klein's Microbiology, 7th ed., McGraw-Hill Higher Education, 2008

[13] Paul M. Dewick, Medicinal Natural Products: A Biosynthetic Approach, Wiley, 1997

[14] Patrik C. Eklund, Otto K. Långvik, Johan P. Wärnå, Tapio O. Salmi, Stefan M. Willför, Rainer E. Sjöholm, Chemical studies on antioxidant mechanisms and free radical scavenging properties of lignans, Organic \& Biomolecular Chemistry, 3, 18, (2005), 3336-3347 http://dx.doi.org/10.1039/B506739A

[15] Hiroe Kikuzaki, Masashi Hisamoto, Kanae Hirose, Kayo Akiyama, Hisaji Taniguchi, Antioxidant Properties of Ferulic Acid and Its Related Compounds, Journal of Agricultural and Food Chemistry, 50, 7, (2002), 2161-2168 https://doi.org/10.1021/jfo11348w
[16] Prasanna Kumara, Sunil K, Arun Kumar B, Determination of DPPH Free Radical Scavenging Activity by RP-HPLC, Rapid Sensitive Method for the Screening of Berry Fruit Juice Freeze Dried Extract, Natural Products Chemistry \& Research, 6, 5, (2018), 1000341 https://doi.org/10.4172/2329-6836.1000341

[17] Lars Müller, Kathleen Theile, Volker Böhm, In vitro antioxidant activity of tocopherols and tocotrienols and comparison of vitamin $\mathrm{E}$ concentration and lipophilic antioxidant capacity in human plasma, Molecular Nutrition \& Food Research, 54, 5, (2010), 731-742 https://doi.org/10.1002/mnfr.200900399

[18] Donghong Liu, John Shi, Alejandra Colina Ibarra, Yukio Kakuda, Sophia Jun Xue, The scavenging capacity and synergistic effects of lycopene, vitamin $\mathrm{E}$, vitamin $\mathrm{C}$, and $\beta$-carotene mixtures on the $\mathrm{DPPH}$ free radical, $L W T$ - Food Science and Technology, 41, 7, (2008), 1344-1349 https://doi.org/10.1016/j.lwt.2007.08.001

[19] Daniel M. Cornforth, Kevin R. Foster, Competition sensing: the social side of bacterial stress responses, Nature Reviews Microbiology, 11, 4, (2013), 285-293 https://doi.org/10.1038/nrmicro2977 